\title{
A review of black seed extract as an agent in the wound healing process
}

\author{
Muhammad Hakeem Mohd Zaid ${ }^{1}$, Muhammad Faezuddin Hanafi ${ }^{1}$ and Muhammad Salahuddin \\ Haris $^{1^{*}}$
}

\section{ABSTRACT}

Introduction: Nigella Sativa or Black Cumin is an annual flowering plant that can be used for wound treatment. In the treatment for wound healing, this plant contains many beneficial components that can help with the treatment but this plant utilisation in the medical field is still limited. This review will provide an overview of the advantages when this plant is used in the wound healing treatment.

Method: The review was based on the ROSES protocol, and the databases used were ScienceDirect, PubMed, and Google Scholar. After the search, only 11 papers had been chosen to be included in the results and they were divided into four main themes that were used for the analysis of the results.

Results: The themes were gross analysis, microscopic analysis, biochemical analysis and antimicrobial analysis.

Conclusion: In conclusion, the black seed extract contains several valuable properties, such as antimicrobial and antioxidant properties, which help improve the wound healing process. Further study needs to be done to discover more potential of Nigella Sativa in treating the wound.

\section{ARTICLE HISTORY:}

Received: 29 January 2021

Accepted: 14 June 2021

Published: 31 July 2021

\section{KEYWORDS:}

Nigella sativa, black seed, wound healing.

\section{HOW TO CITE THIS ARTICLE:}

Mohd Zaid, M. H., Hanafi, M. F. \& Haris, M. S. (2021). A review of black seed extract as an agent in the wound healing process. Journal of Pharmacy, 1(2), 87-96.

doi: 10.31436/jop.v1i2.67

\section{*Corresponding author:}

Email address: solah@iium.edu.my Tel:+6014 3373960

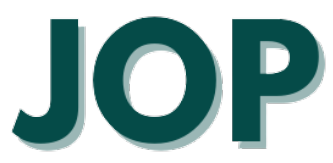

\section{Authors' Affiliation:}

${ }^{1}$ Department of Pharmaceutical Technology, Kulliyyah of Pharmacy, International Islamic University Malaysia, Jalan Sultan Ahmad Shah, 25200 Kuantan, Pahang, Malaysia. 


\section{Introduction}

\section{Nigella Sativa and its bioactive constituents}

New plant-based medicine has emerged and been investigated extensively by lots of pharma companies and researchers. Nigella Sativa or Black Cumin is an annual flowering plant that located in the Eastern Europe (Bulgaria, Cyprus, and Romania) and western Asia (Turkey, Iran, and Iraq). It has been spread into more locations like northern Africa and east to Myanmar (Yimer, 2019). This plant in the family of Ranunculaceae can grow to $20-30 \mathrm{~cm}$ tall and has large, inflated fruits containing lots of seeds. These seeds are usually used as a spice in the food, then gained world recognition as new herbal medicines. Even though the recognition is new, the evidence regarding the usage of Nigella Sativa seeds as traditional medicines can be tracked from the ancient Egypt era (Tutankhamun's era). Another evidence showed that the great Islamic scholar, Avicenna, the Persian physician described Nigella Sativa as a treatment for dyspnoea in his book, Canon of Medicine (Razavi, 2014).

Nigella Sativa seeds have a lot of benefits due to their bioactive constituents. The most significant bioactive component in Nigella Sativa is thymoquinone (TQ) which consist of $30-48 \%$ of the total compounds followed by $\mathrm{p}$ cymene, carvacrol, thymohydroquinone (THQ), dihydrothymoquinone (DHTQ), $\alpha$-thujene, thymol, tanethole, $\beta$-pinene, $\alpha$-pinene, and $\gamma$-terpinene (Sahak et al., 2016). These bioactive compounds can be used as a diuretic, antidiabetic, analgesic, antihypertensive, anticancer and immunomodulatory, anthelmintic, antimicrobial, antiinflammatory, spasmolytic, gastroprotective, hepatoprotective, renal protective, bronchodilator, and antioxidant properties (Ahmad et al., 2013). However, this review paper will only focus on the wound-healing effects that have been produced by the usage of Nigella Sativa and its bioactive constituents.

\section{Wound healing cascade}

Part of the human body can self-regenerated when that area damaged due to internal or external causes and this process is called wound healing cascade. The cascade consists of four stages of wound healing which are the haemostasis phase (blood clotting), inflammatory phase, proliferative phase (tissue growth), and maturation phase (tissue remodelling) (Singh et al., 2017). Each of the stages will differ in terms of the time taken to complete the phase according to the condition of the body, nutrients available, and the surroundings.

The first stage is the haemostasis phase. It begins right after our body is exposed to the injury. The haemostasis from the words ''heme' and 'static' means that the blood and stay, respectively. It means that the haemostasis phase will keep the blood within the blood vessel. This phase will involve the blood coagulation process by recruiting and initiating the platelets to form the blood clot and stop the bleeding (Davies, 2000). After that, the second stage, which is the inflammatory phase, will start. The purpose is to destroy the bacteria involved and remove the debris from the surroundings (Sinno, 2013). To complete this stage, lots of white blood cells (WBC), mostly neutrophils, will be recruited into the wound area. After about three days after injury, another specialised cell called macrophages will continue the work to remove more debris, preparing the wound bed for new tissue growth. Macrophages also will secrete growth factors to facilitate wound healing. After all pathogens and debris are removed, the proliferative phase will begin. This 'stage's objective is to fill, contract, and cover the wound with new tissues. This stage will undergo from day four until day 24. Lastly, after the wound has been closed, the maturation phase will start. During this stage, the wound will be susceptible to interruption caused by both internal and external factors. Therefore, the right healing environment is needed to speed up and optimise the healing process (Mayet, 2014).

\section{Wound healing parameters}

The wound healing process is dynamic. Therefore, to assess wound healing, it needs to be evaluated consistently. There are multiple ways to evaluate the wound healing process: gross observation and monitoring, microscopic evaluation, and biochemical or biomechanical analysis.

The gross observation and monitoring are done by comparing gross observation, geometrical assessments of percentage wound contraction, percentage wound closure, and percentage wound re-epithelialisation, recorded at a specific time interval, between the samples and the control (Singh et al., 2017). However, the gross observation itself does not prove the wound healing as the evaluation can only be done by nothing more than things that the naked eye can see. On the other hand, the microscopic evaluation can assess the wound in a more precise manner. For example, evaluation in histological perspective can be made on the wound healing cascade based on the scab formation from the four stages of the wound healing process (Etulain, 2018, p. 561). Finally, analysis on the biochemical and biomechanical can be used as an assessment for the wound healing process. Recent findings suggested the wound healing impairment is associated with oxidative stress (Dunnill, 2017). Oxidative stress occurs when there are excess free radicals compared to antioxidant enzymes (e.g., superoxide dismutase, glutathione peroxidase, and reductase, catalase.) produced by our body (Rowiński, 2013). As a result, these free radicals will interrupt the wound healing process.

\section{Research gap}

Most of the reviewed paper only focused on the overall ability and advantage of taking the black seeds only. Not much review had been done for the black seed's properties 
in the human model and the animal model. Therefore, this review was done to combine the most recent experiments and research on the black seeds to prove their suitability for wound healing usage. Based on Figure 1, it is depicted the targeted objectives that the authors wanted to emphasise. In the figure, it shows that the black seeds which had many active chemical components can be utilised in the wound healing treatment development due to the properties of the black seeds which can assist and bring many positive effects for the healing process of the wounded area. This review will help to provide some overview of the black seeds' effects on the wound healing process and also provide some evidences for the black seeds to be used in the wound healing treatment. The utilisation of this plant may provide a new solution for the current treatment and improve the outcome of the treatment especially for the special groups that need extra precaution when using certain chemical such as diabetic patients.

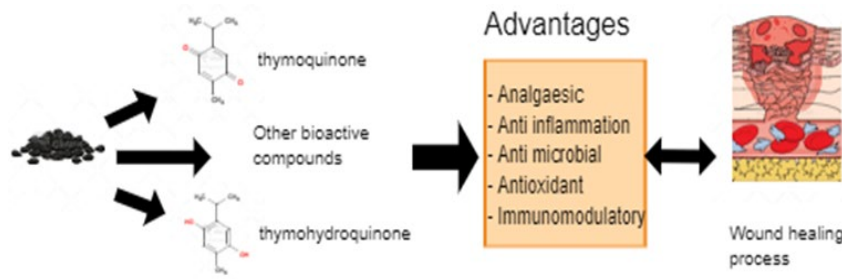

Figure 1: The authors' insight regarding the black seeds' advantages in the wound healing treatment

\section{Methodology}

The study was based on Reporting Standard for Systematic Evidence Syntheses (ROSES) review protocol. The authors start their systematic literature review (SLR) by constructing appropriate research questions for the review. The authors then used the systematic searching strategy, which consists of three-step continuous processes: identification process that used search strings in the selected data bases (Table 1), screening process that used the inclusion and exclusion criteria as mentioned in Table 2 and eligibility process. Then, the authors proceed to the quality appraisal of the selected articles using a specific strategy to ensure the quality of the reviewed articles and the summary of this filtering process is depicted in the Figure 2. Then, the reviewed papers will undergo a data abstraction process that divided the data into four main themes as depicted in the Table 3, and those data will be analysed and validated by both authors to improve the quality of the SLR.
Table 1: Databases and search strings

\begin{tabular}{ll} 
Database & Search strings \\
\hline Google & (Black seed extract OR Black seed \\
cumolar & extract) AND (antioxidant OR \\
& oxidative antagonist OR oxidative \\
& competitor) AND (burns wound OR \\
& blaze wound) AND (healing process \\
& OR curing process OR repair process \\
& OR regenerating process OR rebuild \\
& process) \\
PubMed & "Black seed" or "black caraway" or \\
ScienceDirect & "nutmeg flower" or "roman \\
& coriander" or "Nigella sativa" or \\
& "fennel flower" or "black cumin") \\
& and ("wound healing" or "wound \\
& regeneration" or "wound repair" or \\
& "wound remedy" or "cut healing" or \\
& "cut regeneration" or "cut remedy" or \\
& "laceration healing" or " laceration \\
& regeneration" or "laceration repair" or \\
& "laceration remedy" or "trauma \\
& healing" or "trauma remedy" or \\
& "lesion healing" or "lesion remedy" \\
& or "angiogenesis")
\end{tabular}

Table 2: Criteria for the papers to be included and excluded from this review before the eligibility process

\begin{tabular}{lll} 
Criterion & Inclusion & Exclusion \\
type & $\begin{array}{l}\text { Research } \\
\text { paper, book, } \\
\text { journal } \\
\text { English }\end{array}$ & $\begin{array}{l}\text { Literature review, } \\
\text { encyclopedia, } \\
\text { magazines } \\
\text { Languages other than } \\
\text { English }\end{array}$ \\
$\begin{array}{l}\text { Timeline } \\
\text { Focus of } \\
\text { review }\end{array}$ & $\begin{array}{l}\text { 2016-2020 } \\
\text { Agent of } \\
\text { wound healing }\end{array}$ & $\begin{array}{l}\text { 2015 and before } \\
\text { Other application } \\
\text { other than wound } \\
\text { healing }\end{array}$ \\
\hline
\end{tabular}




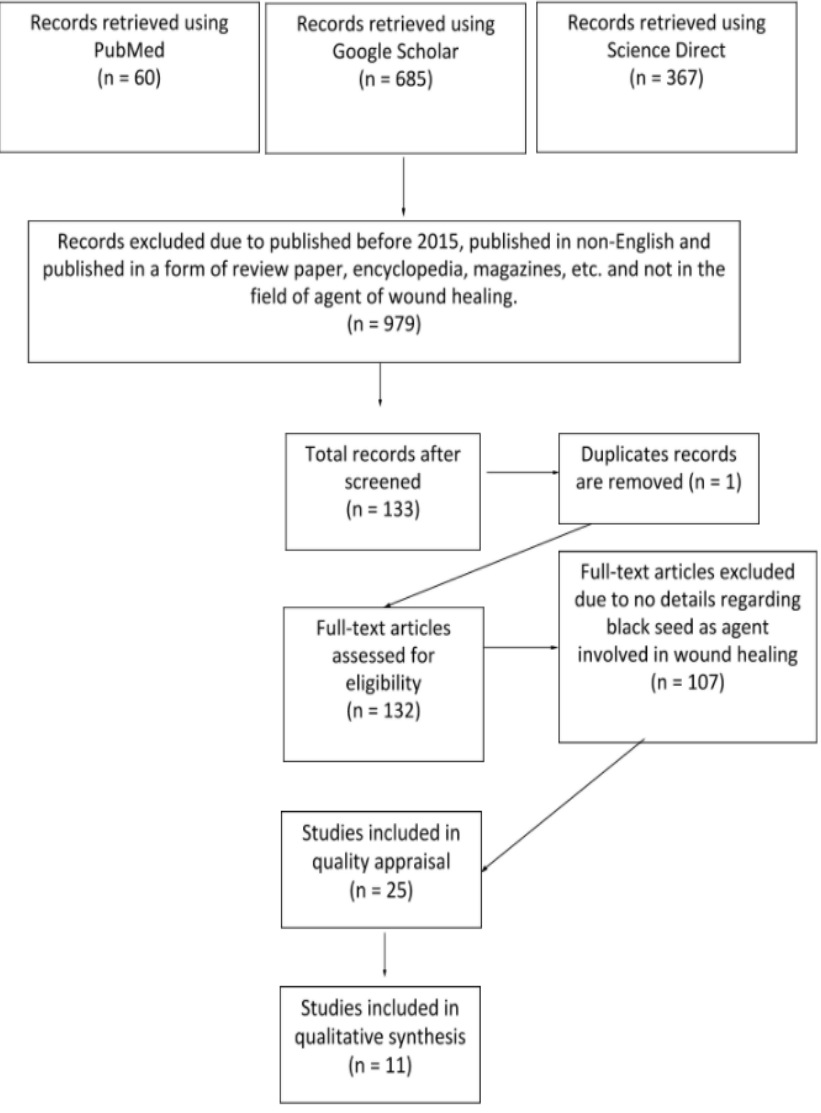

Figure 2: Flow diagram depicted the process for the filtering the papers that will be used for the review

Table 3: Data abstraction of the 11 papers chosen for the review divided into four categories related to wound healing (G: Gross, M: Microscopic, B: Biochemical, A: Antimicrobial)

\begin{tabular}{|c|c|c|c|}
\hline Authors & G & M & B \\
\hline (Kadhim, 2017) & & / & / \\
\hline (Ali et al., 2020) & l & / & 1 \\
\hline (Mastuti et al., 2017) & & & / \\
\hline $\begin{array}{l}\text { (Yalçın Turhan, Mehmet Arıcan, } \\
\text { Zekeriya Okan Karaduman, Ozan } \\
\text { Turhal \& Ozkan, 2019) }\end{array}$ & & & / \\
\hline (Abd Elrahman et al., 2019) & I & / & / \\
\hline (Rohmah \& Suprayitno, 2020) & / & & \\
\hline (Trisnawati, 2018) & & & I \\
\hline (Apaydin \& Gedikli, 2019) & & / & \\
\hline (Nourbar et al., 2019) & / & & \\
\hline (Sallehuddin et al., 2020) & / & & / \\
\hline (Rajabian \& Hosseinzadeh, 2020) & / & I & \\
\hline
\end{tabular}

\section{Results}

Among the 11 selected papers, the results were extracted and divided accordingly to the respective themes. In the gross and microscopic analysis of wound healing, there are four papers used in each theme, while in the biochemical analysis of wound healing, only five selected papers that the results can be put under this theme. Only one paper had results on the antimicrobial analysis of the black seeds. Information extracted from Sallehuddin et al. (2020) and Rajabian \& Hosseinzadeh (2020) will be used in the discussion because these two papers only described the research that other researches had done.

\section{Gross analysis}

Based on Ali et al. (2020), it had stated about the black seeds extract that had been combined with PVA to produce a nanofibrous mat for wound healing purposes. They had observed that the treatment using the nanofibrous mat indeed showed the wound healed without any infections detected on the wound during the execution of the experiment for seven days. Apart from that, Abd. Elrahman et al. (2019) had conducted a study on the healing of teeth sockets in rabbits and had portrayed that the newly formed bone surface area percentage was higher in the rabbits' group which used black seeds oil than the control group. These results showed that the black seeds had better healing properties than the other group, which did not use the oil of black seeds.

Another paper that had studied the effect of the black seeds oil with albumin depicted the fastest wound closure for the first three days was observed when $12 \%$ of the black seeds oil was with the albumin while the longest was observed in the negative control group. These results remained the same on the $5^{\text {th }}$ and the $7^{\text {th }}$ day of the study. The mixture also showed the shortest average wound length during the study. The study showed that the black seeds oil did enhance the wound healing process, and it also assisted in the closure of the wound (Rohmah \& Suprayitno, 2020). Apart from that, an experiment done on diabetic male rats, it was observed that black seeds extract with a concentration of $20 \%$ had an increase in the wound area for the first day of the experiment but kept reducing later in the next few days. The wound was healed completely on the $18^{\text {th }}$ day. As for the extract with $40 \%$ concentration, the observations were the same, but the wound healed on the $15^{\text {th }}$ day which was much quicker than the previous concentration. During the experiment, they found that the rats treated with the black seeds extract had a thicker epidermal layer than the other two groups: the untreated group and phenytoin-treated group. Besides that, they had also found that the wound treated with the extract had much more regularly arranged collagen fibres and fibroblasts than the other groups (Nourbar et al., 2019). 


\section{Microscopic analysis}

In terms of observation under the microscope, Khadim et al. (2017) found that the application of black seeds in combination with propolis and honey showed healing properties when tested using the rabbits' oral mucosa. During the experiment, they found that signs showed the wound started to close with new epithelium on the third day of the investigation. In the dermis layer, they had also observed that the collagen fibres and the fibroblasts had begun to organise within that layer of skin. On the $7^{\text {th }}$ day of the experiment, they managed to capture images of the wound under the microscope, and they found that the epithelium had sealed the wound site. Moreover, the fibroblasts and the connective tissue were already organised in the dermis layer. Another observation had been done on the $10^{\text {th }}$ day of the experiment and they had discovered that the wound site had a thick epithelium layer. The connective tissue was observed to be organised in a good manner. Apart from that, an experiment that used black seeds extracts in a nanofibrous mat depicted that the proliferation phase had been started on the second day of the experiment. This can be observed by the formation of granulation tissue on the wound site that helps increase the production of interleukins. Moreover, the researchers stated that fatty acids from the black seeds in the nano-fibrous mat helped make collagen that can promote the wound healing process (Ali et al., 2020). Besides that, a study used black seeds oil to treat the socket after removing the teeth in rabbits. It was portrayed that the socket applied with the oil had dilated blood vessels while the control group had limited blood supply in the bone marrow. The increase in blood was the indication that active bone formation was occuring when the black seeds oil was used in the treatment. Moreover, the researchers also observed thicker trabecular bone and higher vascular formation in the socket area that had been applied with the black seeds oil. (Abd Elrahman et al., 2019).

Other than that, Apaydin \& Gedikli (2019) had done a study on diabetic rats where the rats were infected with streptozocin and tested with the black seeds essential oil for its wound healing properties. In this study, they emphasised the parts related to the inflammation development, deposition of collagen regeneration of the epithelium, and the formation of new blood vessels. During the $3^{\text {rd }}$ day of the experiment, the researchers had not seen any epithelial formed yet in the three groups of this experiment which were normal rats for the control group, the STZ-DM group (SD) that contained diabetic rats with streptozocin infection, and the STZ-DM+NES group (SDN) that used essential oil on the wound of diabetic rats infected with streptozocin bacteria. They also observed more inflammation, haemorrhagic sites, granulation tissue in the SD group than any other group. Except for the SD group, other groups portrayed a good level of improvement in the wounded areas. Besides that, the SDN group had been observed to have the greatest level of regeneration for the dermal and epidermal layer on the $14^{\text {th }}$ day of the experiment. The wound of the rats was closed completely and there was a formation of sebaceous garland together with the hair follicle at the site of the wound. There was also epithelial, and keratin formed in the SD group, but the level of healing improvement in the group was poorer than the control group. On the other hand, a study that used the black seeds extract in an ointment revealed that the fibroblasts were at the highest quantity when $40 \%$ of the extract (NS-40) had been included in the ointment followed by the $60 \%$ of the extract (NS-60) contained in the ointment. From the analysis using the Mann Whitney statistical, they did confirm that the NS-40 had a significantly higher number of fibroblast than the negative controlled group $(\mathrm{CN})$ together with the NS-60. As for collagen present at the wound site, it was found that NS-60 had the highest amount while the lowest was found in the CN (Mastuti et al., 2017).

\section{Biochemical analysis}

In one of the papers reviewed, the researchers had seen TGF-beta 3 localised and produced by the progenitor cells at the wound site on the third day of the experiment that had used rabbits' mucosa at the oral area. The experiment used black seeds mixed with honey and propolis to be applied at the wound site. Instead of that, other components such as fibrous connective tissue, blood vessels endothelial lining, and fibroblasts had also been seen localised at the wound site. After seven days had passed, they had found that TGFbeta 3 was still detected in the epithelium. Besides that, there were still endothelial cell lining of the blood vessels and fibroblasts observed at the wound site. On the $10^{\text {th }}$ day of the experiment, they detected the TGF-beta 3 localised in the epithelial cells and collagen fibres in the dermis layer (Kadhim, 2017). In another study, the researchers had divided the number of rat specimens into four groups. The $1^{\text {st }}$ group, which was the control group, had used a dressing that had been wet with a saline solution, and the $2^{\text {nd }}$ group was using black seed oil to wet the dressing. The $3^{\text {rd }}$ and $4^{\text {th }}$ group had used a nano-silver solution as the wetting solution with $50 \%$ of the black seeds oil was mixed with the solution in the 3rd group and $50 \%$ concentration of the silver solution was used the $4^{\text {th }}$ group. The study results showed that the highest mean density of collagen was found in the $4^{\text {th }}$ group while the lowest mean vertical scar thickness was observed in the $2^{\text {nd }}$ group. The had deduced this might happen in the $2^{\text {nd }}$ group results due to the black seeds oil had the effect of reducing the free radicals when the wound was inflicted on the specimens (Yalçın Turhan, Mehmet Arıcan, Zekeriya Okan Karaduman, Ozan Turhal \& Ozkan, 2019).

Apart from that, the usage of black seeds oil in the treatment of sockets after tooth removal in rabbits showed that vascular endothelial growth factor (VEGF) significantly increased the experiment and the von Willebrand factor in the experiment was lower than the controlled experiment. These two factors present at the 
wound site can indicate the black seeds oil to be a potential inducer for the formation of new vascular in the wounded area that can help with the wound healing process (Abd Elrahman et al., 2019). The increase in the VEGF had also been seen in an experiment that used the TQ extract from black seeds in treating teeth sockets for diabetic-induced rat specimens (Trisnawati, 2018). In the experiment, group $\mathrm{K}$ was the control group, while the P1 group used the extract mixed with olive oil. Another group which was called the P2 group used $100 \mathrm{mg} / \mathrm{kg}$ of metformin that had been dissolved in distilled water. The early stage of the experiment showed that the P2 group had shown higher VEGF levels than other groups but, on the $7^{\text {th }}$, and $10^{\text {th }}$ day of the experiment, the P1 group was the one with the highest VEGF level (Trisnawati, 2018).

\section{Antimicrobial analysis}

One of the findings in a paper mentioned that the antibacterial resistance was rising as the percentage of black seed extract increased in the nano-fibrous mat made through the electrospinning technique. The researchers stated that this could happen due to thymoquinone (TQ) and thymohydroquinone (THQ) in the extracted samples from the black seeds. They had also mentioned several chemicals in the black seeds, such as carvacrol, thymol, and terpenoids, that can possess potent antimicrobial properties. These chemicals can contribute to the destruction of bacterial cell walls and cause the inside of the bacterial cells to spill out, leading to bacterial death (Mohammed et al., 2019). Some of the bacterial strains such as $S$. aureus and Enterococcusfaecalis cannot form biofilm due to the existence of the TQ while the gram negative bacteria such as E. Coli were less susceptible to TQ and THQ (Halawani, 2009). The chemical can prevent the oxidative activity of the bacteria and reduce the number of bacteria (Ali et al., 2020).

\section{Discussion}

Each of the main themes chosen contributed for the elements targeted for the wound healing treatment. Based on the gross analysis, it can be concluded that black seeds can help with the time taken for the wound to be healed. Most of the results shown that the black seeds can speed up the healing process and making the wound to be closed at faster rate than any other conditions that had been set up in the experiments. For examples Rohmah \& Suprayitno (2020) had founded that black seeds oil with albumin had the fastest wound closure when compared with the negative control group. Besides that, Nourbar et al. (2019) mentioned their research paper that the wound healing was faster as the concentration of the black seeds increasing.

As for the microscopic and biochemical analytsis, it is mainly to see the biocompatibility of the black seeds when used as wound healing agent. The observation was mainly to see if there is any negative changes that can alter the normal cells to regenerated normally. In the analysis, it can be seen that the black seeds can help in reducing the free radicles that can slow down the healing process as founded by Yalçın Turhan, Mehmet Arıcan, Zekeriya Okan Karaduman, Ozan Turhal \& Ozkan (2019). Moreover, it portrayed that the black seeds can also help in the fast regeneration of cells at the wound site by increasing the blood flow to the site and this can be observed based on the research done by Abd Elrahman et al. (2019). Instead of that, there were several other review paper that mentioned the same results as the paper reviewed in this review paper.

In the paper written by Sallehuddin et al. (2020), the author had mentioned the black seeds contained TQ that had many medicinal benefits such as antioxidant, antiinflammatory, antibacterial, and providing protection for the renal as well as for the nerve function. The black seeds also had several good outcomes when they are used as the agent for wound healing. This outcomes happens because the black seeds can induce angiogenesis, the proliferation of fibroblasts, and even increase collagen production. Besides that, some of the papers reported that the black seeds lower down the number of white blood cells and reduce the extent of tissue damage and a bacterial infection. Sallehuddin et al. (2020) also included many relevant papers that depicted the action of black seeds in wound treatments. One of the papers included in the study written by Selçuk et al. (2013) used TQ extracted from the black seeds to treat burn wounds. The results were compared with the burn wound's results treated with silver sulfadiazine (SS) in the same model as previous treatment. The researchers found that TQ had the same rate of wound closure as the SS when administered intraperitoneally. Still, TQ exhibited better healing outcomes than SS when it was administered topically.

Apart from that, a study that had been done by Elgohary et al. (2018) was comparing the black seeds wound healing properties with moist-exposed burn ointment (MEBO) and Chinese traditional herbs when used in the burn wound caused by chemical substances. They had found that all treatments can reduce the wound size with the smallest area found to be treated by black seeds oil. Han et al. (2017) also had obtained the same results when black seed oil was made into a cream and used in the normal wound. In this study, the cream of black seeds oil was compared with Hypericum perforatum (HP) oil cream, and it was observed that black seeds oil cream had almost the same effect as HP oil cream in reducing the wound area and increasing the contraction process of the wound healing.

In excisional wounds, Javadi et al. (2018) had observed that black seeds in combination with honey showed the smallest area of necrotic tissue 20 days after the wound was inflicted. The second smallest area was the wound treated by phenytoin, followed by the group that used honey or black seeds. As for Kumandas et al. (2019), 
they had observed that the black seeds oil cream used in this type of wound had portrayed a slower rate of healing than zinc-silver cream.

Besides that, black seeds had also been experimented with in the chronic delayed wounds by Yusmin and Ahmad (2017). Their study used petroleum jelly as the carrier to administer the black seeds extract on alloxan-induced diabetic wounds. It was seen that contraction of the wound was the greatest for the black seeds group only for the first three days of the experiment. On the $7^{\text {th }}$ and $14^{\text {th }}$ day of the experiment, they had seen the wound contraction was greater in the control group than in the black seeds group. Sari et al. (2018) used the same model, but the black seeds oil was compared with aloe vera (AV) oil gel during the experiment. The gel containing black seed oil affected the wound size after seven days, but it was considered insignificant compared with other groups. Although the results were like those in those experiments, Nourbar et al. (2019) had found the opposite of those results. They observed the fastest rate of healing when black seeds extract was used in the streptozotocin-induced diabetic rats during the experiment. The wound-healing effect was better than phenytoin treatment. The author deduced that the results were varied due to the difference in the mechanism for the death of beta cells in both experiments.

In terms of the microscopic observation, Yaman et al. (2010) observed that vascularisation and epithelialisation were better in the group that used black seed oil for burn wounds than in the SS and control groups. Moreover, granulation tissue formation and the response of antiinflammatory cells were also better in the black seeds group than the rest of the other groups. Besides that, there was a study done by Shahani et al. (2013) on excisional wounds by using rabbits as the test subjects, and the black seeds had produced better angiogenesis and fibroblast proliferation at the wound site.

Furthermore, Selçuk et al. (2013) had observed TQ's good outcomes when applied to burn wounds. The wounds were showing great response for anti-inflammatory cell activity and the good formation of blood vessels, granulation tissue, and epithelial layer. In another study, Han et al. (2017) found that granulation tissue formation and collagen synthesis happens more in the black seeds group rather than in the HP group and the control group but the results for angiogenesis, epithelialisation, and infiltration of inflammatory cells became insignificant when compared with the control group on the $14^{\text {th }}$ day of the study.

Apart from that, Sari et al. (2018) observed less inflammation in diabetic wounds when the test subjects were treated using the black seeds. The wound had less infiltration of polymorphonuclear neutrophil when the black seeds group was compared with the control group. They also observed more fibroblasts had infiltrated into the wound site and more epithelialisation to happen on the $7^{\text {th }}$ day of the study.

With regards to biochemical analysis, it was stated by Cui et al. (2018) total antioxidant state (TAS) and total oxidant stress (TOS) values can be used as the determinants for observing whether oxidative stress was occurring or not. Malondialdehyde (MDA) can also become the determinants for oxidative stress. As for the antioxidant level, glutathione is one of the markers that can be used for observation. Dunnill et al. (2017) had stated that the increase in TOS value and reduction in TAS level could indicate oxidative stress occurrence.

Oxidative stress is vital due to its association with burn wounds (Nielson et al., 2017). Moreover, Vigani et al. (2017) mentioned that antioxidants could reduce the mortality caused by burn injury. Three studies which are done separately by Han et al. (2017), Kumandas et al. (2019), and Selçuk et al. (2013) had observed low TOS level and high TAS level when black seeds and TQ were used for the rat model that a burn and excisional injuries had inflicted. The MDA level was also decreased significantly and both, black seeds and TQ, had greater outcomes in reducing the oxidative stress when compared with SS, HP, and zinc-silver treatments.

Instead of that, another review done by Rajabian \& Hosseinzadeh (2020) had reported that Ahmad et al. (1995), together with Sarkhail et al. (2011) and Mandal et al. (2015) mentioned in their paper about the black seeds oil could help to reduce the time for the healing process of the wound when applied topically. Besides that, Rajabian \& Hosseinzadeh had also reported that Abu-Zinadah (2009) found the usage of black seed oil can improve the state of burn wounds on rabbits' skin. Moreover, in the review, they had written about the study done by $\mathrm{Ab}$ Rahman et al. (2014) about the aqueous extract of black seeds potential in healing wounds. The researchers had observed an increase in the fibroblast's proliferation as well as wound closure activity by the extract. The extract was also observed to be able to scavenge on the free radicals at the wound site. Another study by Abu-Al-Basal (2011) was included in the review. He had mentioned that extract of black seeds obtained by using petroleum ether can provide great healing properties in $\mathrm{BALB} / \mathrm{c}$ mice infected with staphylococcal bacteria. Moreover, the researcher stated that tissue impairment prevention and decreased white blood cell count can be achieved in the study due to the immune-modulating, anti-inflammatory, antioxidant, and bactericidal properties of the extract. 


\section{Conclusion}

The black seeds indeed contain several properties that can help in enhancing the wound healing process. This statement is supported by the results which showed the black seeds is compatible with human body when apply to the wounded area and it can also help to shorten the time for the wound to heal. Both of these outcomes can be observed based on the result analysis from the research papers that were included in this review paper. Moreover, the black seeds also contained antimicrobial properties and anti-inflammation properties that become the advantage of using them in wound treatment. This property may not be found in certain types of synthetic chemicals and it also can prevent any complications that may happen due to unwanted infection or pain cause by the inflammation. Hope that there will be effort to bring this plant into the medicinal world and more research being done to establish its safety in long-term treatment and the usage of this plant's seeds in the patient with comorbidities.

\section{Acknowledgements}

This review was conducted without any funds.

\section{Conflict of Interest}

There was no conflict of interest in this review.

\section{References}

Ab Rahman, M. R., Abdul Razak, F., \& Mohd Bakri, M. (2014). Evaluation of Wound Closure Activity of Nigella sativa, Melastoma malabathricum, Pluchea indica, and Piper sarmentosum Extracts on Scratched Monolayer of Human Gingival Fibroblasts. Evidence-Based Complementary and Alternative Medicine, 2014, 1-9.

https://doi.org/10.1155/2014/190342

Abd Elrahman, S. M., Younes, S. A., \& Kawana, K. Y. (2019). Evaluation of Nigella Sativa on Socket Healing in Rabbits. Alexandria Dental Journal, 44(3), 60-64.

https://doi.org/10.21608/adjalexu.2019.63559

Abu-Al-Basal M. A. (2011). Influence of Nigella sativa fixed oil on some blood parameters and histopathology of skin in staphylococcal-infected BALB/c mice. Pakistan journal of biological sciences: PJBS, 14(23), 1038-1046. https://doi.org/10.3923/pjbs.2011.1038.1046

Abuzinadah, O. (2009). Using Nigella sativa Oil to Treat and Heal Chemical Induced Wound of Rabbit Skin. Journal of King Abdulaziz University-science, 21, 335-346.
Ahmad, A., Husain, A., Mujeeb, M., Khan, S. A., Najmi, A. K., Siddique, N. A., Damanhouri, Z. A., \& Anwar, F. (2013). A review on therapeutic potential of Nigella sativa: A miracle herb. Asian Pacific Journal of Tropical Biomedicine, 3(5), 337-352. https://doi.org/10.1016/S2221-1691(13)60075-1

Ahmed, I. H., Awad, M. A., El-Mahdy, M., Gohar, H. M., \& Ghanem, A. M. (1995). The effect of some medicinal plant extracts on wound healing in farm animals. Assiut Veterinary Medical Journal, 32(64), 236-244.

Al-Gaban, N. M., Ghani, B. A., \& Kadhim, E. F. (2017). Evaluation of Topical Application of Propolis, Black Seeds, and Honey on Oral Mucosal Healing in Rabbits (Histological and Immunohistochemical Study on TGF-33). International Journal of Science and Research (IJSR), 6(2), 1445-1450. https://doi.org/10.21275/ART20164558

Ali, A., Mohebbullah, M., Shahid, M. A., Alam, S., Uddin, M. N., Miah, M. S., Jamal, M. S. I., \& Khan, M. S. (2020). PVA-Nigella Sativa nanofibrous mat: antibacterial efficacy and wound healing potentiality. Journal of the Textile Institute, O(0), 1-11. https://doi.org/10.1080/00405000.2020.1831168

Apaydin, Y. B., \& Gedikli, S. (2019). Wound healing effects of Nigella sativa L. essential oil in streptozotocin-induced in diabetic rats. GSC Biological and Pharmaceutical Sciences, 7(3), 030 039. https://doi.org/10.30574/gscbps.2019.7.3.0095

Cui, X., Gong, J., Han, H., He, L., Teng, Y., Tetley, T., Sinharay, R., Chung, K. F., Islam, T., Gilliland, F., Grady, S., Garshick, E., Li, Z., \& Zhang, J. (2018). Relationship between free and total malondialdehyde, a well-established marker of oxidative stress, in various types of human biospecimens. Journal of Thoracic Disease, 10(5), 3088-3197. https://doi.org/10.21037/jtd.2018.05.92

Davies, J. E., \& Hosseini, M. M. (2000). Histodynamics of endosseous wound healing. Bone engineering, 1(1), 1-14. Retrieved from https://www.researchgate.net/profile/JohnDavies11/publication/255964870_Histodynamics_of _Endosseous_Wound_Healing/links/54dd0e120cf 28 a3d 93 f88e92/Histodynamics-of-Endosseous-WoundHealing.pdf

Davoudi-Kiakalayeh, A., Mohammadi, R., Pourfathollah, A. A., Siery, Z., \& Davoudi-Kiakalayeh, S. (2017). Alloimmunisation in thalassemia patients: New 
insight for healthcare. International Journal of Preventive Medicine, 8, 1-7.

https://doi.org/10.4103/ijpvm.IJPVM

Dunnill, C., Patton, T., Brennan, J., Barrett, J., Dryden, M., Cooke, J., Leaper, D., \& Georgopoulos, N. T. (2017). Reactive oxygen species (ROS) and wound healing: the functional role of ROS and emerging ROS-modulating technologies for augmentation of the healing process. International Wound Journal, 14(1), 89-96. https://doi.org/10.1111/iwj.12557

Dunnill, C., Patton, T., Brennan, J., Barrett, J., Dryden, M., Cooke, J., ... \& Georgopoulos, N. T. (2017). Reactive oxygen species (ROS) and wound healing: the functional role of ROS and emerging ROSmodulating technologies for augmentation of the healing process. International wound journal, 14(1), 89-96.

Elgohary, H. M., Al Jaouni, S. K., \& Selim, S. A. (2018). Effect of ultrasound-enhanced Nigella sativa seeds oil on wound healing: An animal model. Journal of Taibah University Medical Sciences, 13(5), 438-443. https://doi.org/10.1016/j.jtumed.2018.02.008

Etulain, J. Platelets in wound healing and regenerative medicine. Platelets. (2018), 29, 556-568. https://doi.org/10.1080/09537104.2018.1430357

Halawani, E. (2009). Antibacterial Activity of Thymoquinone and Thymohydroquinone of Nigella sativa L. and Their Interaction with Some Antibiotics. Advances in Biological Research, 3(56), 148-152.

Javadi, S. M. R., Hashemi, M., Mohammadi, Y., MamMohammadi, A., Sharifi, A., \& Makarchian, H. R. (2018). Synergistic effect of honey and nigella sativa on wound healing in rats. Acta Cirurgica Brasileira, 33(6), 518-523. https://doi.org/10.1590/s0102-865020180060000006

Kumandaş, A., Karsli, B., Kürüm, A., Çinar, M., \& Elma, E. (2020). Comparison of the effects of zinc-silver cream and nigella sativa oil on wound healing and oxidative stress in the wound model in rats. Ankara Universitesi Veteriner Fakultesi Dergisi, 67(1), 3340. https://doi.org/10.33988/auvfd.563491

MacEwan, M. R., MacEwan, S., Kovacs, T. R., \& Batts, J. (2017). What Makes the Optimal Wound Healing Material? A Review of Current Science and Introduction of a Synthetic Nanofabricated Wound Care Scaffold. Cureus, 9(10). https://doi.org/10.7759/cureus. 1736

Mandal, A. M., Sene, P., \& Manggang, R. K. J. (2015). A Review on Indian Medicinal Plants and Their Role in Wound Healing Activity. World Journal of Pharmaceutical Research, 4(6), 2204-2224.

Mastuti, S., Hadi, D. T., \& Chodidjah, C. (2017). Nigella Sativa Seed Extract Ointment Increasing the Amount of Healing Fibroblast and Collagen on BALB/c Mice. Sains Medika, 8(1), 15. https://doi.org/10.26532/sainsmed.v8i1.1006

Mayet, N., Choonara, Y. E., Kumar, P., Tomar, L. K., Tyagi, C., Du Toit, L. C., \& Pillay, V. (2014). A comprehensive review of advanced biopolymeric wound healing systems. Journal of pharmaceutical sciences, 103(8), 2211-2230. https://doi.org/10.1002/jps.24068

Mohammed, S. J., Amin, H. H. H., Aziz, S. B., Sha, A. M., Hassan, S., Abdul Aziz, J. M., \& Rahman, H. S. (2019). Structural Characterization, Antimicrobial Activity, and in Vitro Cytotoxicity Effect of Black Seed Oil. Evidence-Based Complementary and Alternative Medicine, 2019. https://doi.org/10.1155/2019/6515671

Mirazi, N., Nourbar, E., Yari, S., Rafieian-Kopaei, M., \& Nasri, H. (2019). Effect of hydroethanolic extract of Nigella sativa L. on skin wound healing process in diabetic male rats. International Journal of Preventive Medicine, 10(1), 18. https://doi.org/10.4103/ijpvm.ijpvm_276_18

Nourbar, E., Mirazi, N., Yari, S., Mahmoud, Rafieian-Kopaei, \& Nasri, H. (2019). Effect of Hydroethanolic Extract of Nigella sativa L. on Skin Wound Healing Process in Diabetic Male Rats. International Journal of Preventive Medicine, 1-7. https://doi.org/10.4103/ijpvm.IJPVM

Rajabian, A., \& Hosseinzadeh, H. (2020). Dermatological Effects of Nigella sativa and Its Constituent, Thymoquinone. In Nuts and Seeds in Health and Disease Prevention, 329-355. Elsevier Inc. https://doi.org/10.1016/b978-0-12-818553-7.00024-3

Razavi, B. M., \& Hosseinzadeh, H. (2014). A review of the effects of Nigella sativa L. and its constituent, thymoquinone, in metabolic syndrome. Journal of Endocrinological Investigation, 37(11), 1031-1040.

Rohmah, D. I., \& Suprayitno, E. (2020). Effect of Addition of Black Cumin Seed Oil (Nigella sativa) as 
a Source of Omega-6 on Cork Albumin Powder (Channa Striata) for Wound Closure. International Journal of Scientific and Research Publications (IJSRP), 10(7), 656-662.

https://doi.org/10.29322/ijsrp.10.07.2020.p10371

Rowiński, R., Kozakiewicz, M., Kędziora-Kornatowska, K., Hübner-Woźniak, E., \& Kędziora, J. (2013). Markers of oxidative stress and erythrocyte antioxidant enzyme activity in older men and women with differing physical activity. Experimental Gerontology, 48(11), 1141-1146. https://doi.org/10.1016/j.exger.2013.07.010

Sallehuddin, N., Nordin, A., Idrus, R. B. H., \& Fauzi, M. B. (2020). Nigella sativa and its active compound, thymoquinone, accelerate wound healing in an in vivo animal model: A comprehensive review. International Journal of Environmental Research and Public Health, 17(11), 1-17. https://doi.org/10.3390/ijerph17114160

Sahak, M. K. A., Kabir, N., Abbas, G., Draman, S., Hashim, N. H., \& Hasan Adli, D. S. (2016). The Role of Nigella sativa and Its Active Constituents in Learning and Memory. Evidence-Based Complementary and Alternative Medicine, 2016, 16. https://doi.org/10.1155/2016/6075679

Sarkhail, P., Esmaily, H., Baghae, A., Shafiee, A., Abdollahi, M., \& Sarkheil, P. (2011). Evaluation of Burn Healing Activity of Black Seed Oil in Rats. Planta Medica, 77(12), 34-39. https://doi.org/10.1055/s-0031-1282650

Sari, Y., Purnawan, I., Kurniawan, D. W., \& Sutrisna, E. (2018). A comparative study of the effects of nigella sativa oil gel and aloe Vera gel on wound healing in diabetic rats. Journal of Evidence-Based Integrative Medicine, 23, 1-6. https://doi.org/10.1177/2515690X18772804

Selçuk, C. T., Durgun, M., Tekin, R., Yolbas, L., Bozkurt, M., Akçay, C., ... \& Basarali, M. K. (2013). Evaluation of the effect of thymoquinone treatment on wound healing in a rat burn model. Journal of Burn Care \& Research, 34(5), e274-e281. https://doi.org/10.1097/BCR.0b013e31827a2be1

Singh, S., Young, A., \& McNaught, C.-E. (2017). The physiology of wound healing. Surgery (Oxford), 35(9), 473-477. https://doi.org/10.1016/j.mpsur.2017.06.004
Sinno, H., \& Prakash, S. (2013). Complements and the Wound Healing Cascade: An Updated Review. Plastic Surgery International, 2013, 1-7. https://doi.org/10.1155/2013/146764

Trisnawati, R. (2018). The Effect of Thymoquinone Extract of Black Seeds Toward Socket New Blood Vessels Formation Process After Extraction in Diabetic-Induced Rats. In Research Article Journal of Diabetes and Cholesterol Metabolism (Vol. 2, Issue 1). DCM. Retrieved from http://rpdemos.net/clients/hendunadmin/admin/uploa ds/source/DCM/DCM-18-2-110.pdf

Turhan, Y. 1., Arıcan, M., Karaduman, Z. O., Turhal, O., Gamsızkan, M., Aydın, D., \& Ozkan, K. (2019). Comparison of the Effects of Nigella sativa Oil and Nano-silver on Wound Healing in an Experimental Rat Model. Iranian Red Crescent Medical Journal, 10(10), 1259-1272. https://doi.org/10.5812/ircmj.84650.

Vigani, A., \& Culler, C. A. (2017). Systemic and Local Management of Burn Wounds. Veterinary Clinics of North America: Small Animal Practice, 47(6), 11491163. https://doi.org/10.1016/j.cvsm.2017.06.003

Yaman, I., Durmus, A. S., Ceribasi, S., \& Yaman, M. (2010). Effects of Nigella sativa and silver sulfadiazine on burn wound healing in rats. Veterinarni Medicina, 55(12), 619-624. https://doi.org/10.17221/2948-VETMED

Yimer, E. M., Tuem, K. B., Karim, A., Ur-Rehman, N., \& Anwar, F. (2019). Nigella sativa L. (Black Cumin): A Promising Natural Remedy for Wide Range of Illnesses. Evidence-Based Complementary and Alternative Medicine, 2019, 1-16. https://doi.org/10.1155/2019/1528635

Yusmin, A., \& Ahmad, N. (2017). Effect of thymoquinone on wound healing in alloxan-induced diabetic rats. Asian Journal of Pharmaceutical and Clinical Research, 10(9), 242-245. https://doi.org/10.22159/ajpcr.2017.v10i9.18951 